\title{
Autoritarismo, intolerancia y universidad Acerca del discurso agresivo del sanchecerrismo contra San Marcos en la conyuntura político-electoral de 1931 y la posterior intervención dictatorial en 1932
}

\author{
Tirso Molinari Morales \\ Universidad Nacional Mayor de San Marcos
}

Fecha de recepción 01-08-2018

Fecha de aceptación 05-10-2018

\section{RESUMEN}

En este artículo se presenta aquel discurso agresivo e intolerante propalado por el sanchecerrismo contra la Universidad Nacional Mayor de San Marcos durante la coyuntura electoral de 1931, en el contexto de su enfrentamiento político contra el APRA. Campaña autoritaria que derivó, posteriormente en 1932, en la intervención dictatorial de la Universidad.

PALABRAS CLAVE: Autoritarismo, intolerancia, discurso, universidad, coyuntura electoral, dictadura.

\section{ABSTRACT}

The present article addresses the aggressive discourse of Sanchecerrismo against the National University of San Marcos during the political electoral situation in 1931. It also addresses the dictatorial intervention that followed it in 1932.

KEYWORDS: Authoritarianism, intolerance, discourse, university, electoral situation, dictatorship. 
V amos a presentar aquí dos valiosos documentos publicados por el periódico sanchecerrista La Opinión (Biblioteca Nacional - Hemeroteca) y que corresponden, el primero, a la edición del 21 de octubre de 1931 y, el segundo, a la edición del 22 de octubre de aquel año.

Ambos artículos constituyen un importante testimonio de la grave intolerancia que caracterizó a aquella coyuntura política y que, principalmente, supuso el inicio de toda una sistemática agresividad extremista de Derecha contra el APRA y, en este caso, contra aquellas instituciones, como la Universidad, donde aquel partido tenía, en 1931, una singular influencia entre estudiantes y profesores, dado los vientos antioligárquicos y democráticos-radicales que promovía en los claustros universitarios.

Asimismo, los mencionados documentos presentan una explícita intolerancia, una estereotipada agresividad $y$, sobre todo, un rotundo desprecio autoritario al mundo universitario, tan ajeno al populismo conservador y cuartelarío que caracterizaba el movimiento político sanchecerrista.

Además, estos documentos son un vivo testimonio del inicio de aquel dramático ciclo político confrontacional entre las fuerzas políticas pro oligárquicas y militaristas y el APRA y que aquí tuvo a los claustros Sanmarquinos como escenario de aquella trágica confrontación, a su vez, preámbulo de lo que posteriormente, en 1932 y ya convertido en cruel dictadura, el Gobierno de Sánchez Cerro hará con la Universidad: La intervendrá policial y militarmente, un fatídico 8 de mayo de ese «año de la barbarie», permaneciendo cerrada la Universidad, como lo indica el maestro Basadre, el resto de aquel violento gobierno y hasta 1935 (Basadre, 1969)

Veamos:

Qué pasa con la Juventud Universitaria

No somos conservadores ni enemigos de las efusiones de la juventud. La rebeldía siempre nos merece simpatía, porque gracias a ella se conservan los valores fundamentales de la democracia.

Pero hoy parece que pasara por la universidad un soplo de inconsciencia, una ráfaga de irresponsabilidad.

Es ya la desorbitación lindante con la demencia la que posee a los espíritus juveniles. El sentido de equilibrio se ha alterado profundamente en las masas de estudiantes. Los estudiantes vienen hace algún tiempo ejecutando una serie de actos grotescos, ofensivos a la cultura nacional que revelan un relajamiento de la dignidad humana y que despiertan el estupor de los hombres normales por compresivas que sean las palpitaciones de la juventud.

¿Qué pasa en San Marcos? 
Es la pregunta del día. Los maestros son expulsados so pretexto que pertenecen a partidos conservadores. Nada importa su preparación. Nada su vida de esfuerzo al servicio de la docencia. Nada pues sus actividades pasadas en defensa de los fueros del viejo hogar intelectual.

Para ellos, la juventud de hoy, sólo tiene la burla y el escarnio. Ni siquiera se les concede el derecho al honroso y tranquilo retiro. De esa juventud salen exaltados e irresponsables que van a arrojar piedras a los domicilios de los maestros venerables cuyas efigies son paseadas en procesiones lastimosas entre la algarabía clownesca de los nuevos poseídos que se agitan frenéticamente como enfermos en el baile de San Vito.

Ayer la ciudad de Lima vio desfilar a un grupo de jóvenes estudiantes dándonos el espectáculo de una fúnebre saturnal. Portaban ataúdes con letreros alusivos a hombres e instituciones que ahora constituyen el objetivo de su encono. Contra esos hombres y esas instituciones no tienen otros medios de lucha que la algarada irrisoria y vergonzante. No dan a su campaña la fuerza ideológica de la actitud equilibrada, equilibradamente renovadora que discute e impugna con noble firmeza lo que se considera necesario despejar.

Combate con los más odiosos medios de ataque, con el insulto procaz, con la rechifla aullante, con la caricatura hirientemente grotesca, con la exhibición histriónica de espantajos simbólicos.

A esto ha llegado la juventud, alma mater de la Patria.Y no es sólo esto. Es que esta juventud irreflexiva se deja ganar fácilmente por la demagogia de los farsantes y simuladores de la actitud de izquierda.

Y es por esto que el aprismo se ha introducido en la universidad.

El Aprismo con todo su grotesco ritual de las marchas fúnebres, con su odio sectario, con su demagogia al servicio de la captura del poder.

Los maestros que hoy ejercen la docencia, nada hacen y nada quieren hacer para encausar a la juventud.

Porque carecen de autoridad moral, porque se han resignado a ser cortesanos de la juventud para conservar la mezquina renta de sus cátedras. Y en la Universidad hay un Rector con menos autoridad moral aún que los maestros. Un Rector que ha permitido que anoche después del desfile de la mascarada fúnebre, ofensiva a la cultura nacional se celebre en la Universidad un baile en donde los estudiantes en plena bacanal han tenido horas de orgiástico desenfreno. A ese baile han concurrido todas las hetairas de Lima. Y así la augusta casa venerable ha sido por unas horas frívolo cabaret con orquesta africana, tabladillo de bataclán y serpentinas multicolores» (pág. 3).

Esa era, entonces, la imagen estereotipada de estudiantes, profesores y del mismo Rector que proyectaba La Opinión.

Para La Opinión, en su agresiva intolerancia, ahí donde el Apra tenía alguna influencia se producía una suerte de contaminación política y moral generalizada. 
Así también, si alguien se burlaba del sanchecerrismo y afines y si en esas burlas había, como parece que los hubo, excesos, lo único que cabía, para La Opinión, es una respuesta en la cual se aplasta absolutamente al rival, incluso a quienes sólo se sospecha que están involucrados.

Así pues, se quiere presentar a los estudiantes sanmarquinos, en un contexto de crítica y rebeldía frente al sistema de poder oligárquico (seguramente cargado de actitudes irresponsables que sin embargo no niegan las esenciales perspectivas democráticas y cuestionadoras), como una suerte de jóvenes degenerados y frívolos, a su vez, partícipes descarriados de la tan denostada influencia aprista.

Además, muy estereotipadamente, se presenta a los catedráticos no conservadores como una suerte de adulones y cómplices de una supuestamente generalizada prepotencia estudiantil y lo que es más grave el propio rector, en ese momento el doctor Encinas, es vilmente atacado sin el menor respeto a su dignidad y a su calidad de brillante teórico de la pedagogía moderna.

¿Por qué tanto ensañamiento con el doctor Encinas? Simplemente por ser un intelectual socialista y un demócrata y, por lo tanto, incompatible con ese oscuro populismo autoritario promovido por Sánchez Cerro.

¿Y por qué el odio a los profesores? Seguramente porque muchos de ellos eran apristas o filoapristas. Aquí es muy probable que el objetivo central de tan subalterno ataque sea Luis Alberto Sánchez, en ese entonces uno de los jóvenes catedráticos apristas de mayor proyección en el ámbito intelectual limeño.

Sin embargo, el ataque frontal dirigido en esencia a San Marcos y a lo que en términos de la intelectualidad crítica significaba, no concluye ahí, en el siguiente número de La Opinión, correspondiente al 22 de octubre de 1931, continúa tal ataque pero de una manera aún más frontal. Veamos:

\section{La Universidad es un Recinto de Barbarie}

Uno de los grandes problemas que tenemos delante es el de la instrucción pública. Urge una reforma completa y radical que abarque desde la escuela primaria hasta los institutos de enseñanza superior.

Actualmente la situación es pavorosa. Cada año ingresan a la Universidad miles de alumnos semianalfabetos, ingorantísimos, sin base cultural de ninguna especie. A principios de 1929 el jurado de Admisión de San Marcos presidido por el insigne maestro Dr. Valdizan, presentó un informe acerca de la tarea selectiva que le había tocado realizar. La exposición que en dicho documento se hacía era desoladora. Los postulantes que en esa época se presentaron eran en su gran mayoría de calidad detestable. No tenían nociones elementales de ninguna ciencia. Su instrucción era rudimentaria y adolecían muchos de insuficiencia mental. Además carecían de educación y mostraban influencia de hábitos perniciosos. 
Estas hordas de muchachos ignorantes caen apenas ingresados a la Universidad bajo la influencia de vulgares demagogos que les recargan el entendimiento con el peso abrumador de los lugares comunes. Se les emborracha con palabras.

Muchos de ellos tienen deseos sinceros de aprender. Pero su curiosidad intelectual sin la ayuda de una preparación previa se extraviará en oscuros senderos escabrosos.

Los intelectuales de paga y los estadistas a la violeta se disputan el dominio de los pobres muchachos.

Les excitan el rencor, los impulsan al odio, les fomentan la envidia. Tales mercaderes de pasiones sacan provecho de ellos. Por supuesto los estudiantes se creen revolucionarios. No comprenden el sentido profundo de esta palabra.

No saben que las revoluciones las han hecho siempre los hombres de pensamientos, las mentes lúcidas y frías, los espíritus levantados.

De San Marcos pueden salir un Marat o un Fouquier-Tinville, pero de ninguna manera un Juan Jacobo. La Universidad no es un lugar propicio para la aparición de un Lunacharsky. Sólo impactan los demagogos, los sectarios, las gentes furiosas e intolerantes. Ahí abundan muchos pobres de cultura, muchos mozos incapaces de estudios profundos, de la meditación y el esfuerzo comprensivo.

Los Universitarios aceptaron la reforma leguiísta de 1928 y soportaron alegremente a Denegrí y a McLean. Esos, siendo profesores ayunos de autoridad moral y desprovistos de preparación contaron con el respeto y sumisión de los alumnos. En cambio, tacharon a Víctor Andrés Belaunde, maestro en la más alta acepción del vocablo. El generoso ciudadano que defendió las libertados públicas de 1921 les resulta intolerable. El profesor inteligente y culto les parece odioso. Nosotros sentimos repugnancia por semejante actitud estudiantil.

Nuestra opinión tiene a ese respecto una actitud, una autoridad indiscutible. El Sr. Víctor Andrés Belaunde ha combatido al Comandante Sánchez Cerro. Pero en estas columnas se dá a cada cual lo suyo, con rígida e imparcial justicia.

Es necesario que el problema de la instrucción pública sea abordado con criterio verdaderamente científico. Hay que atenerse a la pedagogía y no a la estridencia demagógica. No es posible que las hordas estudiantiles ignorantes y semibárbaras sigan haciendo lo que les viene en gana, sin el control que existe en todas las sociedades bien constituidas. (Pág. 3).

Como se observa las diatribas contra los estudiantes y profesores son extremas.

Se les califica de «hordas, ignorantes y semibárbaros». Se dice que San Marcos es recinto de «barbarie», que los estudiantes son semianalfabetos y que carecen de la menor educación y cultura y que, por ello, son presa fácil de la manipulación de «vulgares demagogos», etc.

Denostaciones desproporcionadas y apocalípticas que no hacían otra cosa que «validar» futuros planes dictatoriales de clausura de la universidad. Y así fue. De lo que se trataba en realidad, políticamente, era arrasar con la influencia aprista en 
San Marcos y someterla al tutelaje autoritario desde el poder gubernamental. Lo que se pretendía era crear las condiciones para aniquilar las tendencias críticas y contestatarias que se expresaban en San Marcos y que cuestionaban las injusticias estructurales en el país.

Claro, había, a su vez, mucho sectarismo, apasionamiento e incluso arbitrariedades en la dinámica estudiantil. Es el caso de la, a todas luces, injusta tacha a Víctor Andrés Belaunde tan brillante maestro, como Encinas, Sánchez o Valdizán. Pero esas actitudes reprobables eran solo pretexto para el proyecto autoritario y oscurantista que reservaba para San Marcos Sánchez Cerro.

Para él y su núcleo, San Marcos, por lo que representaba intelectualmente y sobre todo dada la influencia aprista, era incompatible con sus concepciones cuartelarias de la educación universitaria y de la política.

\section{Bibliografía}

BASADRE, Jorge (1968). Historia de la República, tomo XIV. Lima: Editorial Universitaria.

PERIódico La Opinión (21 y 22 de octubre de 1931). Hemeroteca de la Biblioteca Nacional. 